\title{
BREEDING STRUCTURE OF A HIGHLY SELECTED CULTIVAR OF CABBAGE (BRASSICA OLERACEA var. (APITATA)
}

\author{
D. J. OCKENDON and LESLEY CURRAH \\ National Vegetable Research Station, Wellesbourne, Warwick
}

Received 29.i.79

\begin{abstract}
SUMMARY
The breeding system of a very uniform open-pollinated cultivar of cabbage, Avon Coronet, was studied by determining $S$-genotype frequencies. In a sample of 52 plants, 24 were $S 2.2,26$ were $S 2.7$ and 2 were $S 7.7$. $S 2.7$ plants were moderately self-compatible, but $S 2.2$ and $S 7.7$ plants were fairly highly selfincompatible. As males, $S 2.7$ plants were fully compatible with $S 2 \cdot 2$, but as females were fairly incompatible. From an analysis of five single plant progenies it was concluded that $S 2.2$ plants produce seed by crossing, while $S 2.7$ plants both cross and self, with about 30 per cent selfing. The breeding system of Avon Coronet appears to be very stable and is unlikely to be altered by further selection for agronomic quality.
\end{abstract}

\section{INTRODUGTION}

Brassica oleracea is basically an outbreeding species with a sporophytic selfincompatibility system. However, many of the cultivated forms of this species inbreed to varying extents. For example, European summer cauliflowers are essentially self-compatible, whereas autumn and winter cauliflowers contain both self-compatible and self-incompatible plants, with the proportion varying considerably from cultivar to cultivar (Watts, 1963; Nieuwhof, 1974; Gray and Crisp, 1977).

Inbreeding is promoted not only by self-compatibility, but also by a decrease in the number of $S$-alleles in a cultivar and by an increase in the frequency of recessive $S$-alleles (Ockendon, 1974). Thompson and Taylor $(1966 b)$ found that the frequency of recessive $S$-alleles varied greatly in seven different cultivated forms of $B$. oleracea and that high frequencies of recessive $S$-alleles were often associated with a higher proportion of partially or completely self-compatible plants. They suggested that changes in the breeding system of $B$. oleracea were a consequence of artificial selection, particularly selection for uniformity, which tends to result in increased inbreeding. Agricultural kale which was morphologically variable had a large number of $S$-alleles and a low frequency of recessive $S$-alleles, whereas kohlrabi was much more uniform and had a high frequency of recessive $S$-alleles. A similar situation was found in Brussels sprouts, where relatively unselected cultivars tended to have more dominant $S$-alleles than highly selected ones (Ockendon, 1974). Information about the number and frequencies of $S$-alleles in a cultivar only gives a rough idea of its breeding system. To obtain a more precise picture, a cultivar was chosen for detailed study, which had partial self-compatibility and only two $S$-alleles of known dominance relationships. The presence of only two $S$-alleles greatly facilitates the identification of $S$-genotypes. The information obtained on 
S-genotype frequencies was used to estimate the amount of inbreeding occurring in the cultivar, and to assess the stability of its breeding system.

\section{MAterials AND METHODS}

The cultivar used was Avon Coronet, a January King type of cabbage (Brassica oleracea var. capitata) which is open-pollinated but almost as uniform as an $F_{1}$ hybrid. The high uniformity was obtained by self-pollination in some generations, followed by pair-crossing or mass-pollination in succeeding generations (Johnson and Faulkner, 1967).

Fifty plants of each of five single plant progenies from a progeny trial (Faulkner, 1976) were transplanted to another field site in November 1975. The plants flowered in May 1976, but many flowered poorly because of drought and attack by pollen beetles. Some plants which could not be tested in 1976 survived until the spring of 1977 and were tested then. A further sample of 52 plants, taken from a crop being grown for the production of breeders' seed, was tested in May, 1978.

For $S$-allele tests, flowers were removed from the plants just before they opened and were kept, with their pedicels in tap-water, in the laboratory. Pollinations were scored as compatible or incompatible by observing pollen tube growth in the styles 18-24 hours after pollination. Styles were fixed in Carnoy's fluid, softened in $1 \mathrm{~N} \mathrm{NaOH}$ at $60^{\circ} \mathrm{C}$, stained in Aniline Blue, and pollen tube growth assessed with a fluorescence microscope (Kho and Baer, 1968).

Previous tests (Ockendon, 1976) had shown that Avon Coronet has only two $S$-alleles, $S 2$ and $S 7$. Flowers from each plant were tested reciprocally with an S2.2 tester line, and with S7.7 as the pollen parent. Plants which were reciprocally incompatible with $S 2$, but compatible with $S 7$, were identified as $S 2.2$. Plants which as female were incompatible with both $S 2$ and $S 7$, but as male were compatible with $S 2$, were identified as $S 2.7$. Plants in which $S 7$ but not $S 2$ could be detected, were assumed to be $S 7.7$.

Self-compatibility tests were made in the field in the same way as the $S$-allele tests, using plants of known $S$-genotype. Cross-compatibility tests were made in May and June 1978 on plants lifted from the field the previous winter and kept in an insect-free glasshouse during their flowering period.

\section{Results}

Pollen tube counts made from reciprocal crosses between $S 2.2$ and $S 2.7$ plants showed that the cross was almost fully compatible when $S 2.2$ plants were used as female, but was mainly incompatible when $S 2.7$ plants were used as female (table 1). Hence in Avon Coronet $S 7$ is dominant to $S 2$ in the pollen but not in the stigma. With $S 2.7$ plants as female, the cross was not always completely incompatible. Plant C8 gave almost no crosscompatibility when tested on 22nd May but gave some cross-compatibility on lst June (table 1). In kale Thompson and Taylor (1966a) found that $S 7$ was dominant to $S 2$ in the pollen, but both alleles were active in the stigma.

$S 2.7$ plants were always markedly more self-compatible than both $S 2.2$ and $S 7.7$ plants (table 2), although neither of these was totally selfincompatible. This condition, in which the heterozygote is more selfcompatible than either of the corresponding homozygotes, is known as 
TABLE 1

Cross-compatibility of Avon Coronet plants. Each pair of plants was crossed reciprocally. The figures for the number of pollen tubes are means of 10-fiower samples

\begin{tabular}{|c|c|c|c|c|}
\hline \multirow[b]{2}{*}{ Date } & \multicolumn{2}{|c|}{ Plants } & \multicolumn{2}{|c|}{ Number of pollen tubes } \\
\hline & $S 2.7$ & $S 2.2$ & $S 2.7 \circ \times S 2.2 \sigma^{*}$ & $S 2.29 \times S 2.7 \sigma^{\circ}$ \\
\hline $18 / 5$ & GI & $\mathrm{C} 20$ & $0 \cdot 3 \pm 0 \cdot 3$ & $21 \cdot 1 \pm 7 \cdot 3$ \\
\hline & C19 & $\mathrm{C} 4$ & $0 \cdot 0^{-}$ & $35 \cdot 0 \pm 5 \cdot 3$ \\
\hline $22 / 5$ & $\mathrm{C} 8$ & Ci3 & $0 \cdot 1 \pm 0 \cdot 1$ & $42 \cdot 5 \pm 2 \cdot 5$ \\
\hline & C3 & C6 & $0 \cdot 0$ & $38 \cdot 2 \pm 4 \cdot 0$ \\
\hline & C5 & Cl1 & $0 \cdot 0$ & $28 \cdot 5 \pm 2 \cdot 2$ \\
\hline $24 / 5$ & $\mathrm{C} 12$ & $\mathrm{C} 16$ & $1 \cdot 8 \pm 0 \cdot 9$ & $43 \cdot 4 \pm 2 \cdot 7$ \\
\hline $25 / 5$ & C18 & $\mathrm{Cl} 3$ & $0 \cdot 1 \pm 0 \cdot 1$ & $43 \cdot 5 \pm 3 \cdot 0$ \\
\hline $1 / 6$ & C8 & C11 & $6 \cdot 1 \pm 2 \cdot 0$ & $61 \cdot 1 \pm 1 \cdot 9$ \\
\hline
\end{tabular}

TABLE 2

Self-compatibility of Avon Coronet plants. The figures for the number of pollen tubes are means of 20-fiower samples ( 4 flowers per plant, 5 plants per progeny)

\begin{tabular}{cccc} 
& \multicolumn{3}{c}{ Number of pollen tubes } \\
\cline { 2 - 4 } Progeny & $S 2 \cdot 2$ & $S 2 \cdot 7$ & $S 7 \cdot 7$ \\
80 & $0 \cdot 3 \pm 0 \cdot 1$ & $14 \cdot 4 \pm 1 \cdot 6$ & - \\
106 & $2 \cdot 3 \pm 0.9$ & $21 \cdot 6 \pm 3 \cdot 7$ & - \\
127 & - & $20 \cdot 4 \pm 3 \cdot 0$ & $4.5 \pm 1 \cdot 6$
\end{tabular}

mutual weakening or as competitive interaction between $S$-alleles (Thompson, 1972).

The results of the $S$-genotype determinations are summarised in table 3 . With the single plant progenies, the $S$-genotype of the female parent can be deduced. Progeny 125 contained all three $S$-genotypes and therefore must have come from an $S 2.7$ female parent. Progeny 127 consisted mainly of $S 2.7$ plants and lacked $S 2.2$ plants, so must have come from an $S 7.7$ female parent. Progenies 12, 80 and 106 lacked $S 7.7$ plants and therefore probably came from $S 2.2$ parents. However, it is possible that one or more of these progenies came from an $S 2.7$ parent, but that the sample tested was too small to detect any of the $S 7.7$ plants which it would have contained. The results for the 1978 mass (table 3 ) indicated that in the cultivar as a whole $S 2.2$ and $S 2.7$ plants occurred at almost equal frequencies, with a slight

TABLE 3

S-genotype frequencies in Avon Coronet. 176 plants tested represented five single plant progenies; 52 plants represented a mass sample from the succeeding generation

\begin{tabular}{|c|c|c|c|c|c|}
\hline \multirow[b]{2}{*}{ Progeny } & \multirow[b]{2}{*}{$\begin{array}{l}\text { No. plants } \\
\text { tested }\end{array}$} & \multicolumn{3}{|c|}{$S$-genotype } & \multirow[b]{2}{*}{$\begin{array}{l}\text { Deduced genotype } \\
\text { of female parent }\end{array}$} \\
\hline & & $S 2.2$ & $S 2.7$ & $S 7.7$ & \\
\hline 12 & 25 & 11 & 14 & 0 & $S 2.2$ \\
\hline 80 & 21 & 8 & 13 & 0 & $S 2.2$ \\
\hline 106 & 44 & 24 & 20 & 0 & $S 2.2$ \\
\hline 125 & 36 & 14 & 20 & 2 & $S 2.7$ \\
\hline 127 & 50 & 0 & 45 & 5 & S7.7 \\
\hline 978 mass & 52 & 24 & 26 & 2 & - \\
\hline
\end{tabular}


excess of the latter, while $S 7.7$ plants had a very low frequency (about 4 per cent).

\section{Discussion}

The two $S 7.7$ plants in progeny 125 (table 3) would have resulted from selfing, suggesting that four of the $S 2.7$ plants and two of the $S 2.2$ plants in this progeny also arose from selfing, and the other 28 plants from crossing. This would indicate a crossing rate of 78 per cent but the accuracy of this estimate is low because it is based on such a small number of $S 7.7$ plants. None of the progenies showed a large excess of $S 2.2$ plants over $S 2.7$ plants, indicating that there was no evidence for marked self-compatibility in the $S 2.2$ plants. This agrees with the pollen tube assessments of the selfcompatibility of these plants.

The evidence presented is consistent with the view that all the seed produced by $S 2.2$ plants results from crossing with $S 2.7$ pollen and the amount of self-seed from $S 2.2$ plants is negligible. Similarly, most of the seed from $S 7.7$ plants arises from crossing with $S 2.2$ pollen, although both the pollen tube data and the $S$-allele determinations show that $S 7.7$ plants may produce a small amount of self-seed. $S 2.7$ plants set seed both by crossing with $S 2.2$ and by selfing and although the pollen tube counts suggest that there would probably be more selfing than crossing, the data for progeny 125 indicate more crossing than selfing. The latter is more likely to be true, because when estimating the degree of incompatibility, pollen tube counts do not always correlate well with seed set data (Gates and Ockendon, 1975). Furthermore, the strength of the incompatibility reaction may be altered by interaction between cross- and self-pollen on the stigma surface (Ockendon and Currah, 1977).

The cross- and self-compatibilities of the three S-genotypes are summarised in fig. 1. The frequencies of the offspring resulting from the compatible combinations can be used to construct a simple model of the breeding structure of Avon Coronet. To simplify the model, the contribution of $S 7.7$ pollen has been ignored as $S 7.7$ plants occur at very low frequency.

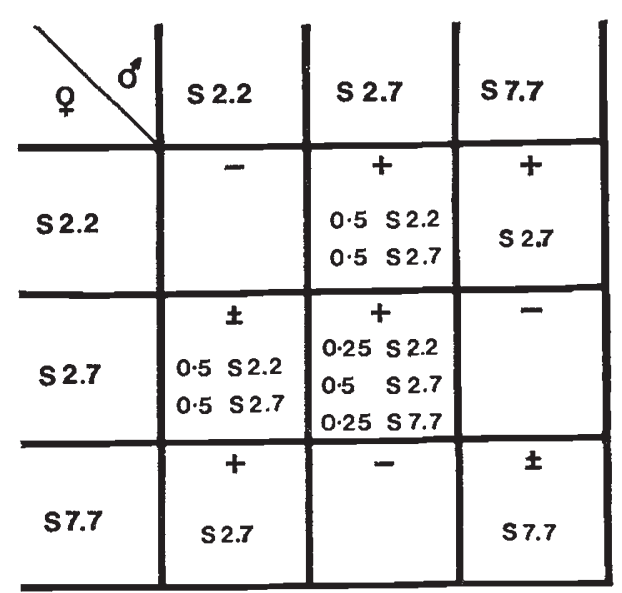

FIG. 1.-Offspring frequencies resulting from selfing and crossing of the three $S$-genotypes in Avon Coronet. Incompatible -, partially compatible \pm , compatible + . 
If $x$ represents the proportion of crossing, then the equilibrium frequencies of the three genotypes, based on fig. 1, will be:

$S 2.2 a=0 \cdot 5 a+x 0 \cdot 5 c+(1-x) 0 \cdot 25 c$

$S 7.7 b=(1-x) 0 \cdot 25 c$

$S 2.7 c=0.5 a+b+x 0 \cdot 5 c+(1-x) 0.5 c$

Given that $a+b+c=1$, values for these three frequencies can then be calculated for given values of $x$. It can be seen that the frequency of $S 2.7$ changes very little over the range of outcrossing $40-90$ per cent, while the frequencies of $S 2.2$ and $S 7.7$ change rather more (table 4 ).

TABLE 4

Equilibrium S-genotype frequencies in Avon Coronet for different rates of outcrossing of $\mathrm{S} 2.7$ plants

\begin{tabular}{cccc} 
& \multicolumn{3}{c}{ Genotype frequencies \% $\%$} \\
\cline { 2 - 4 }$S 2.7$ plants & $S 7.7$ & $S 2.2$ & $S 2.7$ \\
40 & 8.1 & 37.8 & 54.1 \\
50 & 6.6 & 39.9 & 53.3 \\
60 & 5.3 & 42.0 & $52 \cdot 7$ \\
70 & 3.9 & 44.2 & 51.9 \\
80 & $2 \cdot 6$ & 46.1 & 51.3 \\
90 & 1.3 & 48.1 & 50.6
\end{tabular}

The figure of nearly 4 per cent $S 7.7$ plants in the 1978 mass corresponds to 70 per cent outcrossing of the $S 2.7$ plants (table 4 ), while the results of progeny 125 indicated an outcrossing rate of 78 per cent. Considerably larger samples than were used here would be needed for precise estimation of the average outcrossing rate of $S 2.7$ plants as it would be necessary to obtain an accurate assessment of the low number of $S 7.7$ plants in the population.

The amount of outcrossing in Avon Coronet may vary from year to year, partly as a result of variation in temperature (Johnson, 1971; Ockendon, 1973; Visser, 1977) and insect behaviour (Faulkner, 1974). However, if the model is substantially correct, such variations will have relatively little effect on the $S$-genotype frequencies. These frequencies may also be changed by selection of agronomically élite plants for seed production. Unless extremely small numbers of plants were selected, it is likely that any moderate changes in the $S$-genotype frequencies would soon be restored to something similar to the equilibrium condition after a few generations of multiplication without selection. The breeding structure appears to be very stable.

Avon Coronet is one of the first cultivars in which only two $S$-alleles have been reported. The minimum number of $S$-alleles found in an openpollinated Brussels sprout cultivar was four, and some of these cultivars were highly selected (Ockendon, 1974, 1977). There may be some openpollinated cultivars of calabrese in which only two $S$-alleles occur (Ockendon, unpub. obs.), but these cultivars consist of a mixture of self-incompatible plants, and self-compatible plants in which no $S$-allele activity can be detected. Although the $S 2.7$ plants in Avon Coronet are partially selfcompatible, both $S$-alleles can be readily detected. Selection for extreme 
uniformity in a cultivar consisting of self-incompatible and self-compatible plants would be expected to favour the latter and might eventually lead to elimination of all the self-incompatible plants, as has apparently happened in some cauliflower cultivars. That this has not happened in Avon Coronet can be explained by the stability of the breeding system which depends partly on particular features of $S 2$ and $S 7 . \quad S 2$ differs from other recessive $S$-alleles in being recessive in the pollen, but usually fully active in the stigma. In contrast, $S 5$ is completely recessive in both pollen and stigma to a dominant allele such as $S 39$. For example, if a cultivar contained only $S 5$ and $S 39$, the expected genotype composition would be 50 per cent $S 5.39$, and 50 per cent $S 5.5$. The heterozygote would be self-incompatible, but the homozygote partially self-compatible. $S 39.39$ homozygotes would not occur, and if the frequency of $S 39$ dropped as a consequence of artificial selection, it might eventually become eliminated from the population, leaving only self-compatible $S 5.5$ plants. The mutual weakening of $S$-alleles which occurs in Avon Coronet is comparatively unusual. In a study of 128 combinations between $28 S$-alleles in kale, Thompson (1972) found only one combination showing mutual weakening. Two examples were reported in Brussels sprouts by Lawson and Williams (1976), involving $S 7$ with $S 36$ and $S 5$ with $S 15$. Because the $S$-heterozygote in Avon Coronet is considerably more self-compatible than either of the homozygotes it is very unlikely that either $S$-allele would be lost from the population. Hence the breeder can select plants within Avon Coronet on purely agronomic grounds, with little chance of greatly altering the breeding structure of the cultivar by so doing.

$S$-alleles can be useful characters for studying the breeding structures of populations in which they occur, as there is no need to introduce alien marker characters. However, $S$-allele frequencies alone give limited information about breeding systems, unless linked with information about the dominance relationships of the $S$-alleles present and the degree of selfincompatibility of the $S$-genotypes. Although $S$-alleles take much longer to score than visible marker characters, which restricts the size of the samples which can be handled, $S$-allele analysis does provide a very powerful tool for investigating the breeding structure of both natural and artificial populations.

Acknowledgments.-Thanks are due to Miss A. Baker for excellent technical assistance, and to Mr G. J. Faulkner for providing the plant material.

\section{ReFERENCES}

FAULKNER, G. J. 1974. Factors affecting field-scale production of seed of $F_{1}$ hybrid Brussels sprouts. Ann. appl. Biol., 77, 181-190.

FAULKNER, G. J. 1976. Multiplication and testing of NVRS cultivars. In: Rep. Natn. Veg. Res. Stn. for 1975 , p. 33.

Gates, P. J., AND ockendon, D. J. 1975. Seed set and pollen tube growth as a measure of self-incompatibility in Brassica oleracea. Incomp. News., 6, 56-60.

GRAY, A. R., AND CRISP, P. 1977. Breeding system, taxonomy, and breeding strategy in cauliflower, Brassica oleracea var. botrytis L. Euphytica, 26, 369-375.

Johnson, A. G. 1971. Factors affecting the degree of self-incompatibility in inbred lines of Brussels sprouts. Euphytica, 20, 561-573.

Johnson, A. G., ANd faulkneR, G. J. 1967. Winter cabbage. In: Rep. Natn. Veg. Res. Stn. for 1966, p. 22.

KHO, Y. O., AND BAER, J. 1968. Observing pollen tubes by means of fluorescence. Euphytica, 17, 298-302. 
LAWSON, J., AND WILLIAMS, w. 1976. The effect of genotype on levels of pseudocompatibility and the production of improved varieties in Brassica oleracea. 7. hort. Sci., 51, 123-132. NIEUwно, м. 1974. The occurrence of self-incompatibility in cauliflower (Brassica oleracea var. botrytis $\mathrm{L}$. subvar. cauliflora $\mathrm{DC}$ ), and the possibilities to produce uniform varieties. Euphytica, 23, 474-478.

ockendon, D. J. 1973. Selection for high self-incompatibility in inbred lines of Brussels sprouts. Euphytica, 22, 503-509.

OCKENDON, D. J. 1974. Distribution of self-incompatibility alleles and breeding structure of open-pollinated cultivars of Brussels sprouts. Heredity, 33, 159-171.

ockendon, D. J. 1976. Breeding systems. In: Rep. Natn. Veg. Res. Stn. for 1975, p. 23.

ocKENDON, D. J. 1977. Rare self-incompatibility alleles in a purple cultivar of Brussels sprouts. Heredity, 39, 149-152.

ockENDON, D. J., AND CURRAH, L. 1977. Self-pollen reduces the number of cross-pollen tubes in the styles of Brassica oleracea L. New Phytol., 78, 675-680.

THOMPson, K. F. 1972. Competitive interaction between two S-alleles in a sporophytically controlled incompatibility system. Heredity, 28, 1-7.

THOMPSON, K. F., AND TAYLOR, J. P. 1966a. Non-linear dominance relationships between S-alleles. Heredity, 21, 345-362.

THOMPSON, K. F., AND TAYLOR, J. P. 1966b. The breakdown of self-incompatibility in cultivars of Brassica oleracea. Heredity, 21, 637-648.

VISSER, D. L. 1977. The effect of alternating temperatures on the self-incompatibility of some clones of Brussels sprouts (Brassica oleracea var. gemmifera). Euphytica, 26, 273-277.

WATTS, L. E. 1963. Investigations into the breeding system of cauliflower (Brassica oleracea var. botrytis (L.)). I. Studies of self-incompatibility. Euphytica, 12, 323-340. 